\title{
Depression among infertile women in 0gbomosoland
}

\author{
SA Oladeji and AD OlaOlorun* \\ Department of Family Medicine, Bowen University Teaching Hospital, Ogbomoso, Nigeria \\ *Corresponding author, email: olaolorun@buth.edu.ng
}

Background: Infertility is a major medical condition that affects many married couples globally and it has immense psycho-social impact on couples, especially in Africa where a high premium is placed on child-bearing. This study therefore determined the prevalence of and the factors associated with depression among infertile women in Ogbomoso, Southwest Nigeria.

Methods: The study was a descriptive cross-sectional study carried out at the gynaecology clinic of the Bowen University Teaching Hospital using the Patient Health Questionnaire- 9 to screen for and determine the severity of depression as well as assess the social functioning of the respondents. A total of 110 women with infertility were recruited. Data was analysed using SPSS $^{\oplus}$ (version 20) with statistical significance set at less than 0.05.

Results: The study found a depression prevalence of $52.7 \%$. There was no significant association between the age group of the respondents $(p=0.889)$, their level of education $(p=0.731)$, years since marriage $(p=0.38)$, type of infertility $(p=0.873)$, number of living children $(p=0.226)$, sex of the children $(p=0.257)$ and depression. Depression was, however, significantly associated with impairment in social functioning of the respondents $(p=0.005)$.

Conclusion: Depression is a very common co-morbidity in infertile women. It should not only be screened for among infertile women, but physicians attending to such women need to offer psycho-social support as part of care for these women.

Keywords: depression, infertility, social functioning, mental disorder, co-morbidity

\section{Introduction}

While some define infertility as the inability of co-habiting heterosexual couples to achieve conception within a year despite regular, adequate and unprotected peno-vaginal intercourse, ${ }^{1}$ the World Health Organization (WHO) defines it as the inability to conceive within two years of exposure to pregnancy because some couples, though not infertile, may not be able to conceive within the first year of unprotected sex. ${ }^{2}$ It is divided into primary infertility, for women who have never conceived, and secondary infertility, for women who have conceived at least once previously.

Infertility reportedly affects about $13-15 \%$ of couples worldwide, ${ }^{3}$ and between 60 million and 168 million people globally. ${ }^{2}$ It has an immense psycho-social impact on couples, especially in Africa where a high premium is placed on child-bearing. ${ }^{4}$ Women with fertility problems may be despised, neglected or abused by their husbands and extended family. ${ }^{4}$ While adoption may serve as an alternative strategy for some couples, it is not widely practised because of cultural creeds, stigmatisation, financial difficulties and procedural bottlenecks. ${ }^{5}$

In patriarchal societies like Nigeria, infertility is culturally considered as a problem of women, and is a reason for men to marry new wives. ${ }^{6,7}$ Infertility is also believed in Nigeria to be linked with evil spirits, ancestral curses, witchcraft manipulations and promiscuity. ${ }^{7}$ Most of the burden of infertility is borne by women because of a rapid decline in fertility with age, societal pressure and stigma. ${ }^{2}$

Depression is a common mental disorder characterised by depressed mood, loss of interest or pleasure, decreased energy, feelings of guilt or low self-worth, disturbed sleep or appetite, and poor concentration. ${ }^{8}$ Currently, the WHO ranks depression as the fourth leading cause of disability worldwide, and projects that it will become the second leading cause of disability by
2020 , and the leading cause by 2030 . $^{8,9}$ The burden of depression cuts across both high-income and low- and middle-income countries, especially among women. ${ }^{8}$

Parenting is innate for both men and women, and the failure to achieve this naturally and/or spontaneously has been associated with anger, depression, anxiety, marital problems and feelings of worthlessness. ${ }^{10}$ Marital discord may also develop, especially when a couple is under pressure to make medical decisions. ${ }^{10}$ Although normal grief is expected and it often occurs in women with infertility, it may progress to pathological grief leading to depression. ${ }^{11}$ Depression does not only affect the life of infertile individuals; it also impacts on their treatment and follow-up. ${ }^{12}$ While child adoption is an important option for infertile couples, the barriers to its usage in Nigeria include cultural beliefs and practices, stigmatisation, financial implications and procedural bottlenecks. ${ }^{5}$

Depression prevalence among infertile women in Nigeria has been reported to be between $39.5 \%$ and $42.9 \% .^{13-15}$ The age of the woman, primary infertility, duration of infertility and poor social support have been identified as predictors of depression.

Higher rates of depression among infertile women, but with similar predictors, have been reported from nearby Ghana (62\%), and also from Saudi Arabia (53.8\%). ${ }^{11,12}$

\section{The importance of screening for depression}

The importance of screening for depression in women with infertility cannot be overemphasised. It has been documented that women who screened positive for depression are more likely to delay initiating infertility treatment, and less likely to pursue treatment with oral medication or in vitro fertilisation. ${ }^{16}$ The question arises whether these results are similar across rural and urban areas in Nigeria. The previous studies on prevalence of depression among the infertile have been largely from cities; 
consequently we decided to carry out this study in Ogbomosoland, most of which is rural.

\section{Research questions}

(1) What is the prevalence of depression among infertile women in Ogbomosoland, Nigeria?

(2) What socio-demographic characteristics of these infertile women are associated with depression?

\section{Methodology}

This was a hospital-based descriptive cross-sectional study, and respondents were serially recruited using a convenience sampling method. The inclusion criteria were all adult women with complaints of failure to achieve conception after at least a year of adequate unprotected heterosexual coitus, whether or not they had had a child previously. The exclusion criteria included: individuals with major chronic physical or mental health problems, previous head injury and those on contraception. Approximately 10 heterosexual couples with infertility are seen on each clinic day in our gynaecology clinic, and these constituted the study population. Ogbomosoland is an expanse of land consisting of five local government areas, three of which are completely rural. The main town is approximately $86 \mathrm{~km}$ north of Ibadan, the state capital. Our hospital, a 240-bed hospital, is one of two tertiary health institutions in this area, but the hospital has been in existence for 110 years and thus has a dedicated clientele. Patients are drawn from all of Ogbomosoland as well as surrounding towns and villages, even beyond the state. A total of 100 intervieweradministered questionnaires were used for the study. Data collection for the study lasted three months between March 1, 2015 and May 31, 2015.

Data were collected through the use of a pre-tested and validated semi-structured questionnaire incorporating the Patient Health Questionnaire-9, which was used to screen for depression. Patient health questionnaire-9 (PHQ-9) is a nine-item, 27-point score, self-administered or interviewer-administered questionnaire and based on the Diagnostic and Statistical Manual of Mental Disorders, 4th Edition (DSM-IV) criteria. ${ }^{18}$ Depression severity was based on the PHQ-9 scores, which range from 0 to $27 .{ }^{18,19}$ Questions were asked to determine how infertility affected their participation in social events and functioning at work and at home. A 'yes' answer to either of the questions was indicative of effect on social functioning.

Informed consent was obtained from the respondents, and both the English- and Yoruba-language versions of a pre-tested questionnaire were used depending on which of the languages each respondent understood best. The translation to Yoruba was done using the procedure of forward and backward translation by two bilinguists who had experience in both English and Yoruba language and working independently of each other. The first bilinguist did a forward translation to the Yoruba language while the second did a backward translation from Yoruba language to English. A comparison of the new English translation with the original version was then done and necessary modifications were made to obtain the translated version. The pre-testing of the questionnaire was done at the General Outpatient Department of Bowen Teaching Hospital, Ogbomoso to determine the acceptability of the questionnaire and to identify logistical problems in the conduct of the study.

A positive depression screen was defined as either one or both of the first two PHQ-9 questions endorsed as a 2 (more than half the days) or 3 (nearly every day). Depression severity was defined as follows: scores of 0 to 4 defined respondents with no depression while scores of 5 to 9 defined those with sub-threshold level of depression. Scores of 10 to 14 defined mild depression; scores of 15 to 19 defined moderate depression while scores greater than 20 defined severe depression. The social functioning was assessed as: 'not difficult at all', 'somewhat difficult', 'very difficult' or 'extremely difficult'.20 Completed copies of anonymised questionnaires and measurements were collated, coded serially and entered into a computerised database. The data were analysed using the Statistical Package for Social Sciences and Health (SPSS) software package version 20 (IBM Corp, Armonk, NY, USA). The association between two or more categorical variables was cross-tabulated, and the significance of the associations was tested using Pearson's chi-square and Fisher's exact test, with statistical significance set at 0.05 and $95 \%$ confidence interval. Results are reported in prose, tables and pie charts.

Ethical clearance was obtained from the ethics committee of the Bowen University Teaching Hospital (registered with the National Health Research Ethics Committee, NHREC). Written informed consent was also obtained from each participant. They were informed about the nature of the study, and were assured of confidentiality and privacy throughout the duration of the study, and of their liberty to withdraw from the study at any time without any untoward consequence on their care. They were also made aware that there would be no financial reward for participating in the study. The data were stored in passwordprotected laptop computers.

\section{Results}

A total of 110 eligible and consenting women with infertility were recruited for this study. The age range of the respondents was between 24 and 49 years while their mean age was $34.5 \pm 5.7$ years. The prevalence of depression among the respondents was $52.7 \%$.

Table 1 shows the socio-demographic characteristics of the respondents. About two-thirds of the respondents (63.6\%) were aged 30-39 years. A little above half (52.7\%) belonged to social class 2. Three-fifths of them (62.7\%) had a tertiary level of education. About one-half of them (47.3\%) had been married for less than five years while a quarter $(25.5 \%)$ were within five to nine years of marriage. Two-thirds (69.1\%) had no living child while one-fifth had only one child. Some $10 \%$ had only female children while a little above $10 \%(12.7 \%)$ had only male children. Slightly over half (52.7\%) had secondary infertility. The prevalence of depression among the respondents was $52.7 \%$. Sixty women had minimal to moderate depression (Table 1/Figure 1), even though the single largest group ( 49 women) had no symptoms of depression and only one person manifested severe depression. All the women had sought 'spiritual' assistance in terms of prayers, 'hantu' (washings of inked koranic inscriptions, believed to have spiritual healing powers) or herbs prior to their visit to the hospital.

Table 2 shows the factors associated with depression. While young women with infertility had a higher rate of depression $(53.3 \%)$ compared with older women (52.0\%), the association 
Table 1: Socio-demographic characteristics of the married women

\begin{tabular}{|c|c|}
\hline Variables & Frequency $n(\%)$ \\
\hline \multicolumn{2}{|l|}{ Age group (years) } \\
\hline 20-29 & $21(19.1)$ \\
\hline $30-39$ & $70(63.6)$ \\
\hline $40-49$ & $19(17.3)$ \\
\hline \multicolumn{2}{|l|}{ Social class } \\
\hline Class 1 & $13(11.8)$ \\
\hline Class 2 & $58(52.7)$ \\
\hline Class 3 & $39(35.5)$ \\
\hline \multicolumn{2}{|l|}{ Level of education } \\
\hline Primary & $10(9.1)$ \\
\hline Secondary & $31(28.2)$ \\
\hline Tertiary & $69(62.7)$ \\
\hline \multicolumn{2}{|l|}{ Years since marriage } \\
\hline$<5$ years & $52(47.3)$ \\
\hline $5-9$ years & $28(25.5)$ \\
\hline $10-14$ years & $16(14.5)$ \\
\hline $15-19$ years & $10(9.1)$ \\
\hline$\geq 20$ years & $4(3.6)$ \\
\hline \multicolumn{2}{|l|}{ Number of living children } \\
\hline None & $76(69.1)$ \\
\hline 1 & $21(19.1)$ \\
\hline 2 & $13(11.8)$ \\
\hline \multicolumn{2}{|l|}{ Sex of children } \\
\hline None & $76(69.1)$ \\
\hline Male only & $14(12.7)$ \\
\hline Female only & $10(9.1)$ \\
\hline Both male and female & $10(9.1)$ \\
\hline \multicolumn{2}{|l|}{ Type of infertility } \\
\hline Primary & $52(47.3)$ \\
\hline Secondary & $58(52.7)$ \\
\hline \multicolumn{2}{|l|}{ Presence of depression } \\
\hline Yes & $58(52.7)$ \\
\hline No & $52(47.3)$ \\
\hline \multicolumn{2}{|l|}{ Depression severity } \\
\hline No depression & $49(44.5)$ \\
\hline Minimal symptom & $39(35.5)$ \\
\hline Mild depression & $15(13.6)$ \\
\hline Moderate depression & $6(5.5)$ \\
\hline Severe depression & $1(0.9)$ \\
\hline \multicolumn{2}{|l|}{ Other treatment } \\
\hline Spiritual assistance & $110(100 \%)$ \\
\hline
\end{tabular}

between age of infertile women and depression was not statistically significant.

Respondents who had secondary and tertiary education had higher rates of depression ( $54.8 \%$ and $53.6 \%$ respectively) compared with those with primary level of education. The association between the level of education and depression among women with infertility was not statistically significant.

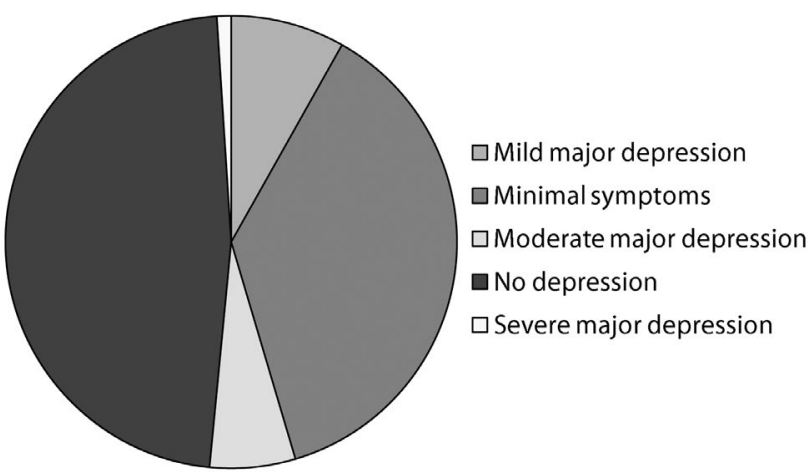

Figure 1: Depression severity.

Table 2: Factors associated with depression among infertile women

\begin{tabular}{|c|c|c|}
\hline \multirow[t]{2}{*}{ Variable } & $\begin{array}{l}\text { Infertile women } \\
\text { with depression }\end{array}$ & $\begin{array}{l}\text { Infertile women } \\
\text { without depression }\end{array}$ \\
\hline & $n=58(52.7 \%)$ & $n=52(47.3 \%)$ \\
\hline \multicolumn{3}{|l|}{ Age group } \\
\hline 20-34 (young women) & $32(53.3)$ & $28(46.7)$ \\
\hline 35-49 (older women) & $26(52.0)$ & $24(48.0)$ \\
\hline \multicolumn{3}{|l|}{ Level of education } \\
\hline Primary & $4(40.0)$ & $6(60.0)$ \\
\hline Secondary & $17(54.8)$ & $14(45.2)$ \\
\hline Tertiary & $37(53.6)$ & $32(46.4)$ \\
\hline \multicolumn{3}{|l|}{ Years since marriage } \\
\hline$<10$ years & $42(52.5)$ & $38(47.5)$ \\
\hline$\geq 10$ years & $16(53.3)$ & $14(46.7)$ \\
\hline \multicolumn{3}{|l|}{ Type of infertility } \\
\hline Primary & 27 (51.9) & $25(48.1)$ \\
\hline Secondary & $31(53.4)$ & $27(46.6)$ \\
\hline \multicolumn{3}{|l|}{ Number of living children } \\
\hline None & $43(56.6)$ & $33(43.4)$ \\
\hline At least one & $15(44.1)$ & $19(55.9)$ \\
\hline \multicolumn{3}{|l|}{ Sex of children } \\
\hline None & $43(56.6)$ & $33(43,4)$ \\
\hline Female only & $6(60.0)$ & $4(40.0)$ \\
\hline At least one male & $9(37.5)$ & $15(6.5)$ \\
\hline \multicolumn{3}{|l|}{ Effect on social functioning } \\
\hline Not difficult & $37(44.6)$ & $46(55.4)$ \\
\hline Somewhat difficult & $18(75.0)$ & $6(25.0)$ \\
\hline Very difficult & $3(100.0)$ & $0(0.0)$ \\
\hline
\end{tabular}

Note: Pearson's chi-square and Fisher's exact test were used to test for statistical significance.

While women with $\geq 10$ years of marriage had a slightly higher rate of depression (53.3\%) than those with $<10$ years of marriage $(52.5 \%)$, the association between depression and the number of years of marriage was not statistically significant.

Women with secondary infertility had a slightly higher rate of depression $(53.4 \%)$ compared with those who had primary infertility (51.9\%); the association was not statistically significant. Similarly, women with no children had a higher rate of depression (56.6\%) compared with those who had at least one child (44.1\%), 
but the association between the number of children and depression was not statistically significant.

While women with no child and those with only female children had higher rates of depression (56.6\% and $60.0 \%$ respectively) compared with those who had at least one male child (37.5\%), the association was not statistically significant.

All respondents who described their social functioning as very difficult were depressed, three-quarters $(75.0 \%)$ of those who described theirs as somewhat difficult were depressed, and less than half $(44.6 \%)$ of those with no difficulty with social functioning were depressed. The association between the social functioning of the respondents and depression was statistically significant.

\section{Discussion}

This study found a depression prevalence of $52.7 \%$ among women with infertility. This was higher than the prevalence reported in previous studies in Nigeria by Ukpong and Orji ${ }^{13}$ who found a prevalence of $42.9 \%$ and lkeako et al. ${ }^{14}$ who found a prevalence of $39.5 \%$, but similar to that of Al-Homaidan ${ }^{12}$ in Saudi Arabia who reported a prevalence of 53.8\%. The reason for this difference might in the instrument used to assess depression (Patient Health Questionnaire). Others have used Beck's Depression Inventory (BDI), the General Health Questionnaire (GHQ) or the Hospital Anxiety and Depression Scale (HADS). ${ }^{12,13}$ The mean age of the respondents was 34.5 years, similar to the findings in other studies from Ibadan ${ }^{15}$ and Awka ${ }^{14}$ in Nigeria. Secondary infertility accounted for the majority of cases (52.7\%), and this was similar to the results of Ukpong and Orji13 in Southeast Nigeria and Awoyinka and Ohaeri ${ }^{15}$ in Ibadan, Nigeria. It is not surprising that women with living children seek more in Nigeria partly because the average number of children per women has been reported at 5.7. ${ }^{21}$ This is especially so if living children are females. Male children are highly desired and valued in Nigeria. Therefore, women without male children might keep desiring further conception until the desire is met.

Unlike the findings in previous studies, ${ }^{11,12,15}$ this study found no statistically significant relationship between the age of the women and depression $(p=0.889)$. This could be because young infertile women could face a similar psychological burden as well as psycho-social pressures to their older counterparts. All the women had had spiritual intervention prior to their hospital visit and this could have had enough salutary effect to blunt any agerelated differences in depression.

Similarly, the study found that there was no statistically significant association between depression in infertile women and the number of years since marriage ( $p=0.938)$, type of infertility $(p=0.873)$, number of living children $(p=0.226)$, sex of children $(p=0.257)$ and their level of education $(p=0.731)$. This was, however, contrary to the findings of Ukpong and Orji ${ }^{13}$ as well as Ikeako et al. ${ }^{14}$ who noted that primary infertility and longer duration of infertility were associated with depression. The reason for these differences may be partly due to different geographical locations and societal beliefs in the areas in which the studies were carried out. Also, that depression in infertile women was not significantly associated with their level of education is not surprising as acquisition of formal education tends to delay planned childbearing ${ }^{22}$ and in this study age of women is not associated with depression.
Depression in infertile women was found in this study to be significantly associated with impaired social functioning such as attending social functions and performing daily routines ( $p=$ 0.005). This finding might be a result of psycho-social pressures that these women could be experiencing periodically from family members as reported by Al-Homaidan et al. ${ }^{12}$ in Saudi Arabia and Farzadi and Ghasemzadeh ${ }^{17}$ in Iran. This study has highlighted the important association of depression with infertility. This could be critical to the successful treatment of infertility.

This study also found that all the women with infertility had at one time or other sought spiritual solutions to their infertility issues. This reflects people's belief in Nigeria that infertility is linked to evil spirits, ancestral spirits and witchcraft., ${ }^{7,22}$

This study has some limitations, one of which is the crosssectional method, which does not allow for causal inferences to be made. Also, the sampling could have been vulnerable to bias as it was not a probability sampling.

\section{Conclusion}

Depression is a very common co-morbidity in infertile women in Nigeria. Therefore, gynaecologists, family physicians and others attending to these women must have a policy of screening for depression and, when needed, offering psycho-social support as part of their overall care of these women, especially if based in a rural area.

Acknowledgement - The authors acknowledge the support of family medicine residents at the gynaecology clinic in recruiting research subjects for this study.

\section{References}

1. Gnoth C, Godehardt E, Frank-Herrmann P, Friol K, Tigges J, Freund G. Definition and prevalence of subfertility and infertility. Human Reprod. 2005;20(5):1144-7. https://doi.org/10.1093/humrep/deh870

2. Tabong PT, Adongo PB. Understanding the social meaning of infertility and childbearing: a qualitative study of the perception of childbearing and childlessness in Northern Ghana. PloS one. 2013;8(1):e54429. PubMed PMID: 23342158. Pubmed Central PMCID: PMC3546987. Epub 2013/01/24.eng.

3. Kamel RM. Management of the infertile couple: an evidence-based protocol. Reprod Biol Endocrinol. 2010;8(1):1.

4. Upkong D, Orji E. Mental health of infertile women in Nigeria. Turk Psikiyatri Dergisi. 2006;17(4):259.

5. Oladokun A, Arulogun O, Oladokun R, Morhason- Bello I, Bamgboye $\mathrm{E}$, Adewole I, et al. Acceptability of child adoption as management option for infertility in Nigeria: Evidence from focus group discussions. Afr J Reprod Health. 2009;13(1):79-91.

6. Dattijo L, Andreadis N, Aminu B, Umar N, \& Black K. Knowledge of Infertility Among Infertile Women in Bauchi, Northern Nigeria. Age (years). 20(13):3.2.

7. Audu DT, Takim AO, Edem C, \& Aernyi RI. Infertility and gender difference in reaction among couples and family and community treatment: a study of patients attending NKST hospital Mkar in Benue state, Nigeria. Eur Sci J. 2013;9(32).

8. World Health Organization. Depression: a global crisis: world mental health day. Geneva: World Health Organization Links; 2012.

9. Kessler RC, Bromet EJ. The epidemiology of depression across cultures. Annu Rev Public Health. 2013;34:119-38. PubMed PMID: 23514317. Pubmed Central PMCID: PMC4100461. Epub 2013/03/22. eng.

10. Deka PK, Sarma S. Psychological aspects of infertility. BJMP. 2010;3(3):336. 
11. Alhassan A, Ziblim AR, Muntaka S. A survey on depression among infertile women in Ghana. BMC women's health. 2014;14(1):1.

12. Al-Homaidan HT. Depression among women with primary infertility attending an infertility clinic in Riyadh, Kingdom of Saudi Arabia: rate, severity, and contributing factors. Int J Health Sci. 2011 Jul;5(2):10815. PubMed PMID: 23267288. Pubmed Central PMCID: PMC3521829. Epub 2011/07/01.eng.

13. Upkong D, Orji E. Mental health of infertile women in Nigeria. Turk J Psychi [Turk psikiyatri dergisi]. 2006 Winter;17(4):259-65. PubMed PMID: 17183442. Epub 2006/12/22. Nijerya'daki Infertil Kadinlarda Ruh Sagligitur.

14. Ikeako L, Iteke O, Ezegwui H, Okeke T. Clinico-demographic indicators of depression among infertile women in a tertiary health institution in Awka, South East Nigeria. Br J Med Medi Res. 2015;7(11):921-31. https://doi.org/10.9734/BJMMR

15. Awoyinka MF, Ohaeri BM. Depression and coping strategies among women with infertility attending three gynaecological clinics in Ibadan. J Biomed Res. 2014;13(2):48-60.

16. Crawford NM, Hoff HS, Merserean JE. Infertile women who screen positive for depression are less likely to initiate infertility treatment. Human Reprod. 2017;32(3):582-7.

17. Farzadi L, Ghasemzadeh A. Two main independent predictors of depression among infertile women: an Asian experience. Taiwan J Obstet Cynecol. 2008;47(2):163-7. https://doi.org/10.1016/S10284559(08)60074-1
18. Adewuyi AL, Oyekale, AS. Assessment of households' environmental safety knowledge and attitudes in Oyo state, Nigeria. Life Sci J. 2013;10(2).

19. Martin A, Rief W, Klaiberg A, Braehler E. Validity of the brief patient health questionnaire mood scale (PHQ-9) in the general population. Gen Hosp Psychi. 2006 Jan-Feb;28(1):71-7. PubMed PMID: 16377369. Epub 2005/12/27. eng.

20. Pence BW, Gaynes BN, Atashili J, O'Donnell JK, Tayong G, Kats $D$, et al. Validity of an interviewer-administered patient health questionnaire-9 to screen for depression in HIV-infected patients in Cameroon. J Affect Disord. 2012 Dec 20;143(1-3):208-13. PubMed PMID: 22840467. Pubmed Central PMCID: PMC3500577. Epub 2012/07/31. eng.

21. Feyisetan BJ, Bankole A. Fertility transition in Nigeria: trends and prospect. New York: United Nations Population Division, Completing the Fertility Transition; 2009. pp. 461-78.

22. National Population Commission. Fertility; 2017. [cited: 2017 Apr 7]. Available from: http://www.population.gov.ng/index.php/82-majoractivities/mdg/101-fertility

Received: 05-05-2017 Accepted: 16-08-2017 